\title{
TOWARD A GENERALLY ACCEPTED VALUATION METHODOLOGY FRAMEWORK
}

\author{
BRUCE MILLS \\ Central Queensland University
}

\section{ABSTRACT}

The valuation profession has long held closeted doubts about its professional status. The art vs science paradigm features regularly in the literature. This collective doubt is attributed in part to the discipline's focus on practice rather than theory, and recognition of the endemic use of imprecise terminology. Responsibility lies with both practitioners and educators but the latter should guide the way forward. The International Valuation Standards address these issues but is it enough? A Generally Accepted Valuation Methodology Framework is proposed to improve levels of understanding by students, practitioners, related professions and clients, thereby contributing to the resolution of these problematic issues.

Keywords: Valuation theory, standards, methodology, methods and framework.

\section{INTRODUCTION}

One of the most challenging tasks for many involved with the property valuation (appraisal) discipline, including clients, students and related professions, is developing a correct understanding of many of the most commonly used terms. Fully appreciating the meaning and subtle difference between terms such as methodology, methods and approach is not readily apparent, but it is essential before valuation problem solving processes can be correctly and confidently applied and/or understood. It is well established that cross discipline and state boundaries have contributed to the level of confusion, but it is also argued that much of the difficulty stems from the past and ongoing misuse of such terms in the working language of practitioners, as well as misrepresentation or imprecise expression in some of the published literature. It could additionally be argued that this ongoing lack of clarity has contributed to the shadow of insecurity that is regularly cast over the status of the profession.

The International Valuation Standards have gone a long way toward correcting these problems, but it is considered that more could and should be done in order to more clearly and correctly explain the meaning and relationship of fundamental property concepts in both practitioner and literature domains. Research of the issues involved has lead to consideration of a Valuation Methodology Framework (VMF) and its potential worth as a learning and teaching tool. Such a framework is therefore presented and discussed below with the aim of exploring, explaining and justifying its content and merits. It is argued that 
the attributes of such a tool will be of benefit to the property profession as a whole, but particularly for existing and future property users, investors and other property related professionals in practice.

\section{THE INTERNATIONAL VALUATION STANDARDS}

The International Valuation Standards (IVS) 2005 were developed by the International Valuation Standards Committee (IVSC). At the time of writing (IVSC 2007), the membership included 43 states along with nine observer States and two corresponding States. Globally influential bodies responsible for setting their own standards such as The Royal Institution of Chartered Surveyors and The Appraisal Institute are represented among its members. The standards produced by the IVSC therefore have global recognition if not yet global adoption. The objectives identified by the IVSC in association with its member states therefore truly represent global initiatives and in brief include; facilitating cross-border transactions, contributing to the viability of international property markets, promoting transparency in financial reporting, promoting reliability of valuations and to serve as a professional benchmark globally.

The IVS (2005) claim and are widely recognised as representing accepted or best practice in the profession and are also known as Generally Accepted Valuation Principles. It is identified within that local differences in regulation and valuation processes exist among some Member States. In these circumstances, it is then the responsibility of practitioners to identify and explain any process variations where and when applicable. The International Valuation Standards Committee (IVSC, 2005, p.7) however limits itself by advising 'Detailed examination of methodology and its application to specific property types or markets is the province of specialist education and literature'. The focus of the standards then is on what valuers do, rather than how they should do it.

Gilbertson (2002) questions this lack of focus on methodology within valuation standards across the various jurisdictions and argues that the IVSC and others need to take a lead and then others would follow. This suggestion becomes ever more plausible as many countries such as Australia and New Zealand mirror ever greater sections of the IVS within their own Professional Practice Standards (Australian Property Institute 2006). There is never the less strong recognition in the IVS of the need for sound problem solving skills for many valuation tasks. Every professional property valuer should possess the ability to develop appropriate methodology and subsequently select the relevant techniques, methods and programs in order to solve the particular valuation problem.

'The International Valuation Standards Committee (IVSC) recognises the complexity of professional valuation procedures, the diversity of property situations, the difficulty other professional disciplines may have in interpreting valuation activities, problems in the usage and translation of terminology, and the 
paramount need of the public for well-founded professional valuations developed in accordance with generally accepted standards" (IVSC 2005, p.11)

It is therefore apparent that explaining the meaning of fundamental terms such as approach, method and methodology as well as identifying how they relate to the valuation process should assist in alleviating some of the identified confusion. In fact, in its discussion on the organisation of the Standards, the IVSC states;

'To foster understanding among professional disciplines and to alleviate the difficulties arising from language barriers, this section aims at providing commentary on basic legal, economic, and conceptual frameworks upon which the valuation discipline and Standards are based.' IVS (IVSC, 2005 p. 11)

It therefore follows that one way to more clearly explain the inherent relationships is to develop a singularly focussed Generally Accepted Valuation Methodological Framework (VMF) that concisely presents the various classifications of terminology and how they relate to each other. Once established, it should make the task of explanation to other interested professions as well as property students and practitioners that much easier, thereby broadening the level of understanding globally. In conjunction with the Generally Accepted Valuation Principles embodied within the IVS 2005, and its incorporated Valuation Process (see the abbreviated versions in Figure $1 \& 2$ below), the VMF should lead to higher levels of consistency and standard of application both now and into the future.

\section{TOWARD AN ACCEPTABLE FRAMEWORK}

Getting general acceptance of anything on a global scale is never easy. At least in this instance, the ground work has been commenced by the IVS and the opportunity now exists to further contribute to its ongoing refinement and development. A full and comprehensive VMF is potentially enormously complex and is likely to require further refinement and development over time. From the outset then, it is considered useful to commence with a more general theoretical model that identifies the major components and their relationships without the additional distraction of the specifics. A suggested VMF theoretical model is presented in Figure 1. 


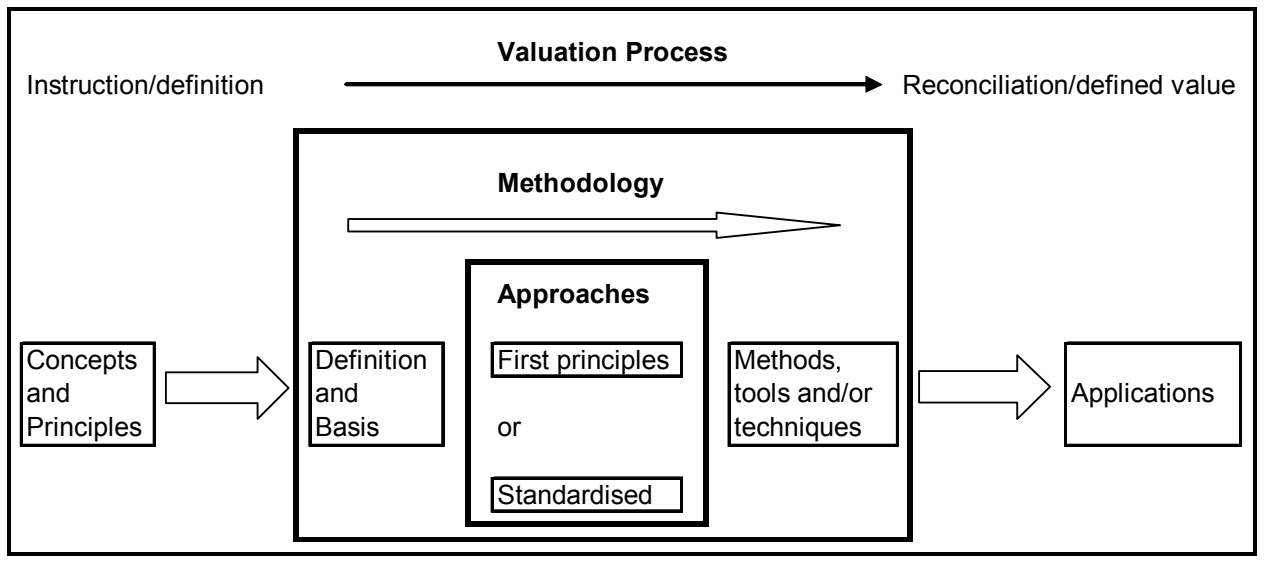

This particular model satisfies a number of fundamental requirements. It is relatively simple and logical in design and therefore fairly easily understood. It incorporates sufficient information to clearly identify the major components and their relationships in association with the established Valuation Process. The detail of each component is the subject of further discussion below which is also further developed diagrammatically by the proposed Generally Accepted VMF in Figure 2. It should be recognised that the detail of the VMF is intended to be explorative rather than exhaustive at this time, and that it will require further and ongoing development. The ensuing discussion endeavours to explain and justify the frameworks relevance as a learning tool for students, clients and property practitioners alike.

\section{VALUATION CONCEPTS AND PRINCIPLES}

The valuation Concepts identified in the VMF are by no means complete. Almost any specific term used in the area of property valuation could potentially be listed. It is however considered important to identify this category of information, if for no other reason than the fact that the term is used frequently in the literature and its place and relationship needs to be established. It should be noted that some of the terms identified in the Concepts section, such as Cost, also feature in other sections. This is important to recognise as the categories within the framework are not mutually exclusive, this being one of the potentially confusing aspects of the property literature. The current IVS (IVSC 2005 , p.19) makes reference to many valuation concepts in its section on General Valuation Concepts and Principles.

The IVS also discusses valuation Principles but only presents Substitution as well as Supply and Demand in any detail. It is interesting to note that concepts such as Highest 
and Best Use as discussed by the IVS are treated by others as Principles. Larsen (2003) identifies and discusses eight principles while Betts \& Ely (2005) discuss eleven. The principles identified in the proposed VMF model are derived from these sources. What is or isn't a valuation Principle is not the point of focus however. Once again, the need to be comprehensive is also not seen to be paramount at this time. It is considered more important to identify each class of information and to cement their relationship in context to each other.

\section{DEFINITIONS OR BASIS OF VALUATION}

The dominant perspective of the valuation profession, particularly in developed western economies, is that definition of value should be segregated into two main classifications, Market Value or Non-Market Value. This is not the view of all interested parties but as we are proposing a valuation profession focussed framework, this is considered an appropriate place to start. Market value is undoubtedly the most commonly used definition because of its relationship to the most common applications. This definition has been widely discussed over a lengthy period and is presented in detail within the IVS.

In contrast, the Non-Market Value category is designed to cover everything else. While this simplistic distinction at the outset is useful for those who rely predominantly on the Market value definition, arguably being the majority of practitioners, it does little to assist in identifying or explaining the complexities inherent in the many Non-market definitions. It also does little to promote the development of the skills necessary in solving some of the more complex property related problems, an area of opportunity for the property profession to demonstrate its complete and often expected skill base.

Whipple (1995) in contrast takes a more complex 'intellectual' view of developing definitions or bases of valuation, and this first principles style, while not as readily applied, does embody some significantly superior attributes. Firstly, because it is based upon a scientific modelling process, it forces the user to be cognisant of the very basis and logic upon which any methodology adopted has been constructed or upon which it relies. Because of this fact, the user needs to make a conscious decision about what methods are applicable and how and why they should be applied, rather than relying on an 'off the shelf' or standardised style Approach, which may or may not be comprehensively applicable or even wholly correct in any particular circumstance.

The basis of Whipple's (1995) Approach relies in understanding the difference between what are termed Positive and Normative definitions of value. Many difficulties associated with varying definitions of value have come about according to Whipple $(1995$, p. 83) because valuers and the Courts have failed '... to distinguish between positive and normative definitions of value and methods of valuation. Note the two predicates: definitions and methods.' And further, the rules of precedent applicable to the courts compounds inappropriate decisions and the failure to correctly distinguish between the 
two '.. definitions of value has arguably caused as much mischief in valuation as Keynes attributes to economics'.

\section{Figure 2: Generally Accepted Valuation Methodology Framework (VMF)}

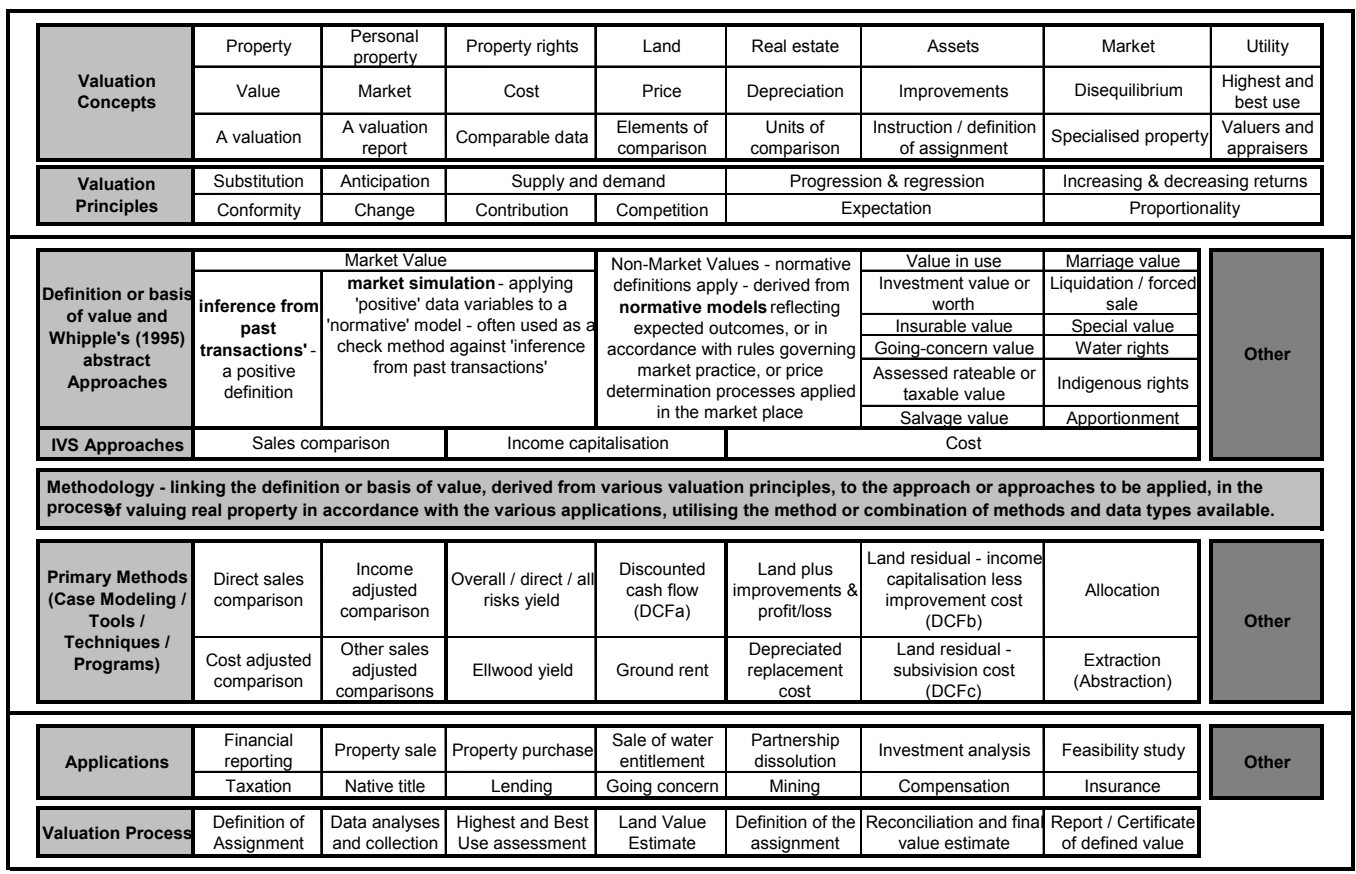

So what is the difference? In essence, a Positive definition of value such as Market Value is based upon actual evidence researched within the market place, an interpretation of 'what is' occurring. In contrast, a Normative definition of value should be applied when there is no directly comparable market evidence available. The definition therefore needs to be designed and constructed around what information is available and what 'should' or could be expected to apply. Its design should reflect a scientifically reliable model of the expected behaviour in the circumstance and rely upon sound theoretical principles and constructs.

Some such methodologies have lead to the development of well known methods and/or techniques such as the Hypothetical Subdivision technique. While this technique is now a widely recognised generic tool, there are many different formats and methods of application in practice. In association with the inherent variables applicable to several common components, each application of the method should be constructed based upon the individual circumstances. This process reflects a Normative or modelled Approach to 
establishing the basis of valuation, but it should also be recognised that there are likely to be Positive contributions to some component parts such as the market price of saleable units.

\section{APPROACHES TO VALUATION}

The use of the term Approach seems to be one of the most misunderstood aspects of the valuation literature in general. It is described by the IVS as,

'The term valuation approach refers to generally accepted analytical methodologies that are in common use. In various States these approaches may be referred to as valuation methods.' (IVS 2005, p. 33)

This statement is however not literally correct as only one of the three identified Approaches described by the IVS, the Sales Comparison Approach, is actually a complete stand alone methodology in its own right. Having said that, this is also only the case in certain circumstances; when directly comparable market sales or 'twins' (Fischer, 2002) exist that require no further significant adjustment. If adjustments are required with perhaps a sales adjustment grid for example, these adjustments will most likely incorporate methods more directly associated with Cost and/or Income Approaches.

This variability in application of each Approach occurs because each can rely, but not always, on methods or techniques that are conceptually more directly associated with one of the other alternative Approaches, this varying relationship being identified and described in Table 1. In fact, the valuation problem solving task, other than the most common applications, regularly requires the valuer to consider and subsequently select from a variety of analytical tools available having regard to the particular application and circumstance involved (IVS 2005, p.35).

\section{Table 1: Valuation approach relationships}

\begin{tabular}{|c|c|}
\hline $\begin{array}{l}\text { Sales } \\
\text { approach }\end{array}$ & $\begin{array}{l}\text { Dependent on units of cost and/or income for sale price adjustment or } \\
\text { comparison technique. }\end{array}$ \\
\hline $\begin{array}{l}\text { Cost } \\
\text { approach }\end{array}$ & $\begin{array}{l}\text { Dependent on income and sales data components for analysing cost adjustments } \\
\text { and segregating land or building value. }\end{array}$ \\
\hline $\begin{array}{l}\text { Income } \\
\text { approach }\end{array}$ & $\begin{array}{l}\text { Dependent on market based sales for comparison and/or development cost } \\
\text { inputs or otherwise lacks credibility. }\end{array}$ \\
\hline
\end{tabular}

In contrast, Whipple's (1995, p. 59) so called 'intellectual approach' relies on what is referred to as a first principles or scientific modelling approach. Once again there are three Approach's identified, the first being 'inference from past transactions', which is 
directly comparable to the IVS Sales Approach including the same limitations and reliance on other types of information. The second, 'simulation of the most probable buyer's price fixing calculus' or Market simulation, relies on the detailed analysis of past market transactions in order to determine reliably comparable variables. In other words, inference from past transactions is required but the degree of complexity involved necessitates more detailed and complex analysis. The third approach, 'Normative modelling' was described previously. In brief, it is also applied when there is a lack of directly comparable market data and it relies on logically defensible models and what should or could be expected to occur in the market.

In order to add further clarity, it could be said that the IVS Approaches are meant to approximate 'Off the shelf' or 'Ready made' standardised methodologies that require only minor adaptation. In contrast, a first principles approach relies on the development of specific and individual problem solving methodologies. The IVS approach has a strong level of appeal, particularly for many valuation practitioners, in part perhaps because it is conceptually more simplistic. It is also perhaps because the most commonly used Sales approach has very little difference to its alternative 'intellectual approach', 'inference from past transactions'.

In other words, it makes comprehension and application easier by not requiring practitioners to grapple with scientific modelling considerations. This is fine when it suits the situation of a buoyant market with adequate directly comparable sales to draw upon for evidence, but far from satisfactory once this evidence becomes scarce, or the property involved differs from the more common stand alone or multi unit residential markets. It does in effect clearly delineate two very distinct levels of complexity in valuation theory, application and practice.

\section{THE MEANING OF THE 'OTHER' IN APPROACHES TO VALUATION}

Many examples of valuation oriented literature could be cited wherein use is made of common terms but with different meanings intended. The Department of Environment, Sport and Territories and Department of Finance (DEST \& F) (1995) is a good example whereby the term Approach is used to classify various methods and techniques used for valuing environmental resources. The three categories used were Market value approaches, Surrogate market approaches and Simulated market approaches (not to be confused with Whipple's 1995 Market simulation above). For the purpose of completeness and in order to emphasise the difference in meaning, these Approach classifications and their related techniques or methods are presented in Table 2. 
Table 2: Techniques to value environmental resources

\begin{tabular}{|l|l|l|}
\hline Market value approaches & Surrogate market approaches & Simulated market approaches \\
\hline $\begin{array}{l}\text { The change-in-productivity } \\
\text { technique }\end{array}$ & The travel-cost technique & Contingent valuation \\
\hline $\begin{array}{l}\text { The change-in-income } \\
\text { technique }\end{array}$ & The property-value technique & The trade-off game \\
\hline $\begin{array}{l}\text { The replacement-cost } \\
\text { technique }\end{array}$ & The wage-differential technique & $\begin{array}{l}\text { Contingent ranking and contingent } \\
\text { rating }\end{array}$ \\
\hline $\begin{array}{l}\text { The preventative-expenditure } \\
\text { technique }\end{array}$ & The proxy-good technique & The priority-evaluator technique \\
\hline The relocation-cost technique & & \\
\hline
\end{tabular}

Source: DEST \& F (1995)

At this point, it is sufficient to know that none of the five techniques identified in the Market value approaches category relies on any methods or techniques in common with the IVS definition of Market Value, or is in any significant way similar to the IVS Sales (or Market comparison) approach. It is also interesting to note the replacement-cost technique in this Market Value category also bares little resemblance to the IVS Cost approach, its emphasis being on the estimated cost of restoration of roads, rivers and water storages subsequent to land degradation damages.

Some of the techniques identified in the DEST \& F market value approach category do however rely on elements of productivity, income, cost and expenditure; attributes that form part of techniques used in association with the IVS Income and Cost Approaches. The Property-value technique within the Surrogate Market Approaches is the closest to the IVS Sales (or Market) comparison Approach. It relies on a statistical analysis of price sensitive characteristics derived from the comparison of total price and characteristic variances. Property valuers would generally describe this as a sales comparison adjustment grid process, whereby the price of the variable characteristics was determined by several comparison techniques, including statistical analysis such as regression.

\section{THE MEANING OF THE 'OTHER' IN METHODS AND APPLICATIONS OF VALUATION}

It is generally recognised that there are numerous methods and applications of valuations and that they continue to expand and evolve. Hyam (2004, p. 113) cites Callinan J in Boland v Yates Property Corp Pty Ltd (1999) 74 ALJR 209 to 268, who previously said at 267;

There is no legal precedent that purports to, or could close for all times the categories of methods of valuation which might be acceptable in a particular case... Valuation practice is, however, like legal practice an evolving discipline. 
As time has passed different types of businesses, different uses to which property may be put, changing financial markets, and more sophisticated and different methods of obtaining financial information and applying financial criteria call for flexibility, resourcefulness and different methods of making valuations.

The Generally Accepted VMF lists several of the more common applications of valuations. Similarly, the more common methods/tools/techniques/programs (grouped as such to promote recognition of their common related meaning) are also listed. Once again, the framework does not propose to be exhaustive but primarily endeavours to add value by identifying the most common. This aspect is further emphasised by the presence of the Other box in both categories. Identifying the Other aspect also increases the flexibility of the framework by making it adaptable to future developments and evolution.

It is interesting to note French's (2005) comments about ongoing changes brought about by the IVS. It was observed that the United Kingdom has gone from 14 definitions of value bases applicable in the past to only one basis of valuation now - market value. The demotion of the Depreciated Replacement Cost (DRC) from a basis of valuation (definition) to the role of humble method was a particular point of interest.

For a relatively recent review of valuation methods, see Pagourtzi, Assimakopoulos, Hatzichristos and French (2003). It is also pertinent to note their reference to the significance of having clear and unambiguous understanding of terminology by all parties. It is therefore unfortunate that the article uses the terms method, models and approach almost interchangeably, as this practice in itself does little to promote clarity. The methods they present are separated into two groups, Traditional and Advanced and for the purposes of completeness are presented in Table 3.

\section{Table 3: Traditional and advanced methods of valuation}

\begin{tabular}{|l|l|}
\hline Traditional valuation methods & Advanced valuation methods \\
\hline * comparable method & * artificial neural networks (ANNs) \\
* investment/income method & * hedonic pricing method \\
* profit method & * spatial analysis methods \\
* development/residual method & * fuzzy logic \\
* contractor's method/cost method & * autoregressive integrated moving average \\
* multiple regression method & \\
* stepwise regression method & \\
\hline
\end{tabular}

Source: Pagourtzi, Assimakopoulos, Hatzichristos \& French (2003)

The basis of their Traditional category is claimed to be if the method relies on some form of comparison technique such as direct comparison or various regression analyses. The 
other Advanced methods category is described as those methods that try to analyse the market by directly mimicking market players thought processes and therefore tend to be more quantitative. The similarity to Whipple's (1995) Normative methods category should not go unnoticed. In passing, it is however difficult to understand why the Profits method is placed within the Traditional category, particularly as the authors identify that this method relies on detailed market analysis rather than direct comparison.

Another 'field' of valuation undergoing considerable ongoing development that also best fits into the Other category of the VMF methods and applications is that of automated valuation models (AVMs). The use of such techniques in the relatively recent past has primarily been for the purpose of providing mass valuations for various property rating and taxation purposes. An ongoing increase in technological capacity, availability of information and the ability to manipulate data in association with a variety of value adding spatial information systems, has more recently lead to a greater application of the models to other sectors. This has been particularly evident with the residential finance sector and its related value to property investors as well as internet based property information providers.

As pointed out by Gilbertson and Duncan (2005),once commenced, it is difficult to retreat from advances in technology. Their coverage of recent developments in regard to AVMs is worthy of particular note. It is agreed that ongoing development and application of such techniques will undoubtedly continue, particularly as future directions will most likely be very much influenced by the bottom line economic imperatives of clients and the supply characteristics of competing valuation firms. Both client service standards as well as the availability of qualified staff will also influence these developments into the future. Irrespective of the current limitations of applying such techniques in the market to tasks such as low risk residential mortgage valuations, even the removal of this work from the hands of valuation firms could potentially have a serious impact on the level of demand for this particular type of valuation work.

\section{THE VALUATION PROCESS}

Examination of the full detail of the established Valuation Process is not considered warranted as part of the VMF model as this has been done comprehensively already by others including the IVS. It is however arguably the single most important link between theory and practice and an abbreviation of it is considered to be a worthwhile inclusion within the framework. This is particularly thought to be appropriate having regard to the totality of the frameworks explanatory intent.

\section{DISCUSSION}

As valuation applications and associated methods and other market dynamics continue to develop over time, it is very probable that demand for valuers' services will also change. 
While the totality of these changes is difficult to predict, it is very possible that much of their activity will be focussed more so on complex valuation problem solving rather than on the more straight forward residential type valuations. Gilbertson and Duncan (2005) identified a range of other possible opportunities for valuers including various intangible products that would fit into the Other category of the VMF's applications component.

As these opportunities unfold, valuers and their clients will become ever more reliant on the ability to solve a variety of complex valuation problems. Success in this regard will be very much dependent on the level of mastery of first principle style methodological constructs. It could even eventuate that those who have not attained or maintained their professional skills in this respect could well fall by the wayside or at the least find themselves in much less demand.

Yet another consideration for concern with potential new applications is the implications for risk management and professional liability. A valuer's ability to adequately demonstrate their capacity to act in these more complex areas, particularly if their career to date has been primarily focussed on a steady diet of residential mortgage valuations, could very well be strenuously tested. This also raises implications for future professional development training and the opportunities and responsibilities of the training providers, including industry, private and university based.

As identified by Boyd (2007), university education providers are already experiencing difficulty in incorporating additional property related specific components in contrast to more generic coverage of related topics. Perhaps the solution will ultimately reside in the development of specialist postgraduate alternatives or similar in service just in time professional development options provided by employers, associations or others. In this context as well, a comprehensive VMF will assist in mapping the total skill base and perhaps become a useful tool in the development or prioritisation of associated curriculum development.

Much of the concern and insecurity of the valuation discipline in relation to its professional status can be directly attributed to its collective level of understanding of the scientific basis, including the theories, principles, concepts and methodologies that bind its practice together. A relatively recent review of North American appraisal (valuation) literature spanning over 100 years, focussing on major handbooks, manuals, and anthologies found that the theory of value is systematically neglected. The authors concluded 'Appraisers face the challenge of erecting the edifice of basic concepts, laws and principles in appraisal so the field can advance from art to science, and from trade to profession' (Canonne \& MacDonald 2003 p. 113).

It was further argued that a neglect of theoretical aspects would inevitably lead to a decline in intellectual rigour, contribute further to the present landslide of fuzzy thinking and imprecise language, resulting in further use of confused terminology. In the event that steps are not taken to arrest such declines, these symptoms will become more prevalent 
and resultant problematic issues are likely to become more frequent and extreme, particularly if/as the valuation profession ventures ever wider into potentially new developing areas of application. It will prove very difficult for the profession to go forward into new areas if it does not have a sound base from which to launch such endeavours. Reinforcing the collective understanding of the theoretical bases of the profession is therefore seen as a necessary step before new directions can be approached with the degree of confidence and reliability required.

As new applications are developed and taken on for clients, where then should the responsibility lie for differentiating between the potential varying levels of skill required by practicing valuers? Will it be a continuation of the status quo whereby much of the onus is placed on valuers themselves to determine their adequacy to accept various instructions, or perhaps it will be a matter of 'let the client beware'. At the very least, professional valuation organisations will be required to enter the debate on the basis of at least setting minimum education and entry level requirements. This will be an increasing challenge in such a dynamic and globalised professional environment and tools such as a Generally Accepted Valuation Methodology Framework may well prove invaluable in developing such minimum standards.

\section{CONCLUSION}

Few would argue that the IVS has not gone a long way toward achieving its stated objectives, but some have suggested that it should do more? The author argues that it could, and has therefore proposed an additional explanatory tool, a Generally Accepted Valuation Methodology Framework (VMF) to assist in this regard. By identifying and mapping the inherent relationships between the main terms, concepts, methods and applications, it should promote a better understanding and application of the methodology available for solving the increasingly diverse and complex array of valuation problems that exist. This is not only relevant to the very real complex problems that exist now, but also the increasing array of potential new applications of valuation theory that will be ongoing into the future.

It is also hoped that a clearer and reinforced enunciation of the scientific theory and modelling behind valuation practice will also assist in alleviating the valuation professions own diminished sense of professional status. A consequential elevation in the perceptions of the valuation profession held by its peers and clients should also follow, in association with a better opportunity to position itself for future opportunities. At the very least, it should contribute to a generally increased and more consistent understanding of the methodology that links valuation theory to its practice and the related development and design of future valuation professional development content and curriculum. 


\section{REFERENCES}

Australian Property Institute (API) (2006), Professional Practice, API, Deakin, ACT.

Betts, R. and Ely, S. (2005), Basic real estate appraisal, $6^{\text {th }}$ edn, Thomson south-western, Ohio.

Boyd, T. (2007), Bridging the gap: a graduate training program for the property industry in Australia, Pacific Rim Real Estate Society Annual Conference, Perth, Australia.

Canonne, J. and MacDonald, R.J. (2003), 'Valuation without value theory: a North American "Appraisal" , Journal of Real Estate Practice and Education, Vol 6, Number 1; ABI/INFORM Global, pp 113-162.

Department of Environment, Sport and Territories and Department of Finance (DEST \& F) (1995), Techniques to value environmental resources - an introductory handbook, AGPS, Canberra.

Fischer, D. (2003), Property valuation methodology, Black Swan Press, Perth.

French, N. (2005), 'Editorial - Market value and depreciated replacement cost', Journal of Property Investment and Finance, Vol 22, Issue 6, p 393.

Gilbertson, B. (2002), 'Valuation or appraisal: an art or science?', Australian Property Journal, Vol. 37, Number 1, pp 11-13.

Gilbertson, B. and Duncan, P. (2005), 'Practice briefing: A vision for valuation', Journal of Property Investment and Finance, Vol. 23, No. 2, pp 123-140.

Hyam, A. (2004), The law affecting valuation of land in Australia, $3^{\text {rd }}$ edn, The Federation Press, Sydney.

International Valuation Standards Committee (IVSC) (2007), website, www.ivsc.org/ (January 2007).

International Valuation Standards Committee (IVSC) (2005), International Valuation Standards, 7th edn, IVSC, London.

Larson, J. (2003), Real estate principles and practice, John Wiley, Hoboken, NJ.

Pagourtzi, E. Assimakopoulos, V. Hatzichristos, T. and French, N. (2003), Real estate appraisal: a review of valuation methods, Journal of Property Investment and Finance, Vol. 21, Issue 4, pp 383-401.

Whipple, R.T.M. (1995), Property valuation and analysis, The Law Book Company, Sydney. 